\title{
The Needed Fire Science
}

\author{
H. W. EMMONS \\ Division of Applied Sciences \\ Harvard University \\ Cambridge, Massachusetts 02138, USA
}

Since there have been many review articles on many aspects of Fire science and its applications (1-10), this paper will stress the many aspects of Fire Science not yet complete or in some cases not even started. By now (1985), it has become broadly accepted that the way of the future in Fire Engineering is through various levels of modeling, aided by the modern computer. A number of models exist for various aspects of a fire in an enclosure (11-14) the most advanced of which are gradually becoming sufficiently general (15-21) to include a fire in any of man's structures. These include both zone and field models. At the same time the U.S. Forest service has developed a fire model sufficiently accurate to have been incorporated into a special hand held calculator usable in the field (22).

Any fire model is, of course, based upon the available understanding of the phenomena of fire and the fire properties of the materials involved. The "understanding" may be based upon secure fire science, secure empixical correlations, or, if these are not available, then the best guess we can make. The ultimate purpose of fire science is to remove the guesswork. Similarly for data, we should know exactly what matexials are present, in what amounts and what configurations, and we should have a complete handbook of the appropriate properties over the appropriate temperature range. Again it is frequently necessary to supplement available data by one's best guess. Anyone engaged in practical fire protection engineering will know that in design it is never known exactly what will be in a new building. And after a fire, it is very rare that the exact contents of the burned building is clear. In fact building changes ovex the years have generally not been documented, so the exact nature of the structure itself is often only illy known.

When we solve technical problems, it is only sensible to keep all phenomena (terms) down to some minimum size and to discard the rest. It takes a high level of scientific understanding of fire to know exactly what aspects of the fire environment are important and which are not.

This insight into the real needs of a practical problem is presented to the fire researcher in a difficult form. How deep do we have to carry our fire research? We all know that while turbulent flow occurs throughout fire dynamics, and a better understanding of fundamental turbulent flows would be useful, the basic turbulence problem is so complex and progress is so slow that little use of fire research funds for this purpose is justifiable. As fire researchers, we should follow such fundamental work (23) so as not to miss some important new discovery in the field. Vaxious approximate methods of computing fire turbulent flows are being developed $(24,25,26)$. These methods will play an increasingly important part in fire research. They will serve to check various approximate 
calculations used in zone model computer codes. They will become increasingly important as the computer continues to increase in capacity and speed. In the same way, chemical kinetics is at the core of all reactions (fire and otherwise) but again many very basic chemical kinetic problems should be followed but not made part of fire research. Those kinetic studies with a bearing on ignition, extinguishment, soot and toxic specie production are clearly important. It is part of the task of the fire researcher to choose his study on those parts that are important (and interesting) rather than merely interesting.

For example, it is well known that the pyrolysis of complex organic materials often produces hundreds of organic compounds $(27,28)$. Having learned this and measured them for a few cases, we can safely say that for now we have enough of such general chemical detail. We should always considex the answer to the question, "What would I do with the additional information if I had it?". Furthermore while the thousands of kinetic steps between these hundreds of compounds are of chemical interest, only the controlling steps or perhaps only overall kinetics in ignition, extinguishment, and special specie production are important for fire.

\section{IGNITION}

While the details of ignition can be traced fox any specific case by balancing the kinetic heat production and dynamic heat loss, fire modeling at present does not use more than ignition temperatures. This approach will probably serve most practical purposes forever but special cases should be done better. The real world presents many peculiar cases of fire ignition (29-39) not now well understood so that a lot more ignition studies are needed to clear up these mysteries. These studies may be chemical kinetic, or dynamic but in most cases must eventually be both.

\section{THE FIRE}

Once a fire is started, we need sufficient information to quantitatively predict three things: the rate of fire spread over the given material in the given configuration, the rate of pyrolysis, and information about the pyrolysis products.

We know the general nature of the energy feedback system which heats and ignites material ahead of an advancing flame front and many special cases have been studied (40-51). The really important question before us is "will it be possible to develop a sufficiently accurate general theory of flame spread that we can use it with confidence in place of correlated test results?". Flame spread is a near surface problem. The rate of pyrolysis often involves phenomena in depth. The simplest case involves evaporation of a liquid fuel or melt of the unzipping of a polymer. Knowing the feedback energy in excess of internal. heat conduction together with a latent heat is sufficient to compute the rate of pyrolysis for simple cases. At present this same approach is often used generally even when not really appropriate.

Many solid fuels char and/or melt and this leads to gxeat complications. Char generally adheres to the solid and protects the virgin material from direct receipt of the feedback energy. The chemical pyrolysis step now occurs below the char layer. Thermal transport processes now control the feedback; and mass transport processes control the removal of the gaseous pyrolysis products. Diffusion through the char and, when porous, deeper into the virgin fuel are initially important. As the char becomes thicker, its change of dimensions and resistance to flow cause it to crack. Finally the gaseous pyrolysis products 
may further pyrolyze as they diffuse through the hot char or are overtaken as the pyrolysis region moves deeper into the solid fuel. Sometimes the resistance to pyrolysis gas flow is so high that pressure builds up below the char which is then expelled explosively. The analysis of the charring process has just begun (52-56). A proper treatment of cracking has not been attempted and nothing has been done with the theoretical and experimental study of, nor the statistics of the explosive removal of char. In fact, it is not yet clear whether or not the pyrolysis process can be adequately treated as an energy absorbing, infinite reaction rate front, or must be treated as a chemical rate controlled region of significant thickness. In either case, the thermal removal of absorbed water is an important first step for wood (53).

Some solids melt at temperatures near their ignition temperature. This may mean that a horizontal surface of the solid melts and pyrolyzes downward faster than the fire spreads horizontally over the surface (cellular polystyrene) (57). It also means that the fire behavior of melting solias is very sensitive to orientation. In fact thin sheets or cloth of such materials may fail to burn when hung verticaliy because they melt at a lower temperature than they ignite. Thus the flames coming up from the burning section melts the virgin material above the burning zone and the burning section falls away and burns out. Nothing has been done to study this process.

On othex materials, wood, polyurethane foam, etc, the fire advances over the surface far fastex than the advance in depth giving rise to a slightly dished burning area $(53,57)$.

The detailed chemical kinetics of pyrolysis is far too complex to expect successful prediction of the rate or composition of the pyrolysis products from empirical chemical kinetics or quantum mechanics in the near future. Realistically what do we really need to know?. As the pyrolysis gases are released, they mix with air and burn (at least partially). We must know the amount of heat thereby released because this energy is what propagates the fire. We need to know the flame energy radiated. Since this depends primarily on the amount of soot present, it would be important to understand soot production. At present measured flame temperatures and emission coefficientsare used to compute the energy radiated (58) or else we assume that some fraction of heat release (say 35\%) (2, 59). is radiated away. Our fire predictions will be more accurate when we fully understand and can quantitatively predict soot production.

In a recent meeting on soot production nine excellent research papers were presented (1). The diverse results remind one of the nine blind men describing an elephant. This remark is not a reflection on the quality of soot research being done but is an observation on the complexity of the problem. Further work will eventually find the key which can put all of the present pieces together into an accurate soot algorithm.

Almost nothing is known about the lel and uel (flammability limits) of the pyrolysis products obtained from various. fuels nor the heat released when they burn. The usual assumption that their heat of combustion equals that of the virgin fuel must, at least for charring fuels, be very bad.

The rate of pyrolysis is essential knowledge because the gases thus produced are the fuel in the flames. There are two basic approaches. First, there is the use of some simple theory. So long as the flow is laminar, the predictions using the svab-Zeldovich transformation are in good agreement with experimental results (60-64). These theories assume a heat of pyrolysis using the feedback energy as the pyrolysing mechanism. This is adequate for evaporating liquid fuels and some non-charring solids but new theories with validating expeximents 
are needed for charring solids. Second, there is direct use of experimental data. The Rate of Heat Release is directly measured at one or several radiant levels and used to predict fire development $(65,66)$. These are engineering test methods and are in need of careful scientific study so their exact significance and use can be based on a thorough understanding of their limitations. It is to be expected that the further development of both the theory and the experiments will bring these two approaches together.

Various special problems have received some attention (67-70). The problem of smouldering is one devoid of all the complex dynamics of aix supply and flames. However, only limited progress has been made $(32,71,72)$ because the complex pyrolysis chemistry plays a central role.

Once the flammable gases are released by pyrolysis they rise and burn in a flame. Although considerable effort has been expended $(73,74,81,82,86,122$, 123 , 131). we are a long way from understanding the full process of flame combustion. All of the quantities required for fire modeling, soot production, radiation, fraction of heat release, residual unburned fuel and toxic products are now obtained from incomplete (for this purpose) experimental results (138). A11 of this required information will be supplied by a complete theory of diffusion flames although some of the information may forever best be obtained empirically because of the joint complications of chemical kinetics and turbulence.

Since many pyrolysis gases are not immediately burned, the content of toxic substances needs to be known. Carbon monoxide, hydrogen chloride, and hydrogen cyanide are the toxic compounds sometimes considered. While a few other compounds acetaldehide, acrolein, are mentioned, they are almost never measured. In fact the compounds usually measured, $\mathrm{CO}, \mathrm{CO}_{2}, \mathrm{H}_{2} \mathrm{O}, \mathrm{O}_{2},\left(\mathrm{C}_{2} \mathrm{H}_{2}\right) \mathrm{x}$, are selected as much by the existence of convenient instruments as by their importance.

Such composition measurements are very important to be made after, smouldering and flaming combustion as well as in pyrolysis alone. In fact, such measurements in the flaming mode need to be known for fire vitiated atmospheres (not nitrogen vitiated). since some burning always occurs in the hot layer of gas at the ceiling. There is only limited data of any of these types for the many fuel types and fuel combinations encountered in practice. At present all that can be done in fire modeling is to use data from any source available and to use it as though it were universal,

\section{PLUMES}

The simple point, line, and area source plume theory together with its experimental validations is good enough for present fire modeling (75, 76). This does not mean that there is no more to learn. The conditions in the plume close to the fuel surface are badly described by present theory (77). The concentration of the pyrolysis products is high and probably absorbs a significant fraction of the flame radiation on its way back to the fuel surface. This feedback radiant energy must be accurately known if we are to predict the pyrolysis rate accurately. There has been no careful detailed study of this radiation absorption aspect of plume flow.

Recent measurements show that the ambient air entrainment rate immediately above the fuel correlates with the vortex shedding frequency. However, what it is, that determines this frequency is a mystery $(77,78)$. 
A few studies of a plume against a wall, in a corner, or at a vent have been made $(79,80)$. None of these problems have been carried to the point that well validated algorithms exist for model fire predictions. This is especially true of the plume near a vent where no reliable data exists (80),

The theory of the burning by a flame in a plume is very unsatisfactory. The present theories which vary from simple entrainment ideas (81) to complex $\varepsilon, k, g$ turbulence and probability controlled reactions (82) fall far short of the needed knowledge. Burning efficiency, residual products including unburnt fuels, soot content, temperature and radiation output are now all determined by a few measured results on a few fuels used as though they were universal. Many more measurements are needed but until a proper correlating theory is developed these measurements are not likely to result in a reasonably universal predictive system.

Many special cases have been considered (83-91). New 2- and 3-dimensional calculation methods used in research should greatly improve our understanding of special plume problems $(90,91)$.

\section{LAYERS}

Fire models to date assume the formation of two homogeneous layers; a hot one above and a cold one below. The fire conditions for which this is adequate is not at present known. What is known is that the fire plume striking the ceiling flows outward in all dixections as a ceiling jet, The initial plume has such small buoyancy that by the time it strikes the room walls the jet is cooled off and its residual momentum carries it downward setting up a general room circulation (92). This initial period is of little importance for further fire development but is important in fire detector operation. Fires often grow fast enough to almost immediately replace the general room cixculation by hot and cold layers. The mixing between these layers appears to be unimportant except during hot layer burnout (30) in which much of the oxygen fox burnout is buoyantly brought up from below. However mixing does occur where wall cooled hot layer gases flow downward into the cold layer and/or upward into the hot layer (93, 94) and where vent flows do some mixing by entrainment (86). The first of these effects need experimental validation while the second needs more studies under a wider range of circumstances.

The hot layer composition changes with time as products of partial combustion collect and the oxygen is more or less used up. At present only low accuracy is attainable not only because pyrolysis products are imperfectly known but also because the inefficiency of plume burning in fire vitiated air is not weII understood.

A recent study (30) has shown that the Lechatelier (95) formula for the burning limits for the layer mixture of flammable gases holds for a thin ( $<20 \mathrm{~cm}$ ) hot layer independent of its oxygen content. Oxygen is drawn up from the cold layer by buoyancy as needed to burn the layer fuels. However the present limited results make it likely that for a much deeper layer the burning would be confined to a sublayex at the interface since only limited oxygen could be brought up from below. There is as yet no verification of this idea first because there has been no careful appropriate experimental work with a deep layer and second because no theory of any kind as yet exists for the layer interface combustion "plumes".

The cold layer while relatively insensitive to a fire cannot be ignored. It changes temperature by addition of small amounts of hot layer gases and is 
significantly heated by the floor (which in turn is radiatively heated from the flames and hot layer). Furthermore there is a slow accumulation of pyrolysis products by the mixed hot layer gases and most importantly by the gases from the pyrolyzing but not yet ignited hot floor. In the limit, one would expect the ventilation limited fire in a room to consist of a rich mixture hot layer extending to the floor with an air flame (air burning in a fuel atmosphere) issuing from the vent into the room at the floor while at the same time a fuel flame issues from the hot layer at the top of the vent onto the ceiling of the next room. There are no research results either theory or experiments on these problems known to this author.

\section{THE CEILING JET}

The ceiling jet from a plume is of only small importance in a small room. In a very large room the assumption of two heterogeneous layers has a serious effect upon the fire growth prediction. Since a lot of feedback energy to ignite new fuels comes from the hot layer, an object in a large room far from the initial fire would ignite almost as soon as a nearby fuel if the hot layer were homogeneous.

This effect is especially bad when a fire plume issues from a fire room into a corridor. The time delay in reaching the far end of the corridor is often of major importance.

Most ceiling jet theories and measurements to date (96-99) assume a steady state. Only a few theoretical studies are nonsteady (100, 10, 101). A simple examination of a nonsteady ceiling jet in a corridor shows (102) that the jet front moves at the rate $u_{f}$

$$
\frac{u_{f}}{\sqrt{g H}}=(I-R)^{1 / 2}(I-\Delta)
$$

where

$$
\begin{aligned}
& R=\frac{\rho}{\rho_{a}} \\
& \Delta=\frac{\delta}{H}
\end{aligned}
$$

relative to the fluid in front of it and has a depth related to the flow rate in the jet and below it given by

$$
\Delta^{2}-2\left\{1-\frac{M_{D}+\frac{M_{u}}{R}}{(1-R)^{1 / 2}}\right\} \Delta+\frac{M_{u}}{R(I-R)^{1 / 2}}=0 \text {. }
$$

But the flow and depth of the ceiling jet layer produced by the fire plume are not in general equal to these values (96). Thus there will generally have to be a jump in the initial shooting jet not to its tranquil flow regime but to the shooting flow appropriate to the advancing ceiling jet given by equations 1 and 2. New experimental studies in a long corridor with a smooth ceiling will be required to validate the above results. In addition, however, the nonsteady ceiling jet must eventually include friction, heat transfer, entrainment, and 
reaction before it is complete. Most of this experimental work has not been started.

It is, of course, possible to use various 3-dimensional nonsteady codes $(20,100)$ to analyze the ceiling jet growth. However, until computers with perhaps 1000 times present capacity become generally available (and cheap), these approaches are impoxtant research tools and for occasional special cases but are not practical for general fire engineering.

\section{VENTS}

The buoyant flow from a fire room through a vent, in the form of an opening in a vertical wall has received considerable attention (103-106). Present knowledge is adequate in the sense that many other parts of fire science are in so much more urgent need of attention. However, a numbex of vent flow problems remain. For example, if there are two layers (hot and cold) on both sides of a vent the pressure differences can cause six different flow layers, two outflows and two inflows. This may or may not be of importance to the real fire, but for a fire model it can exist and the computer must be told what to do. Some available fire models already handle this case well. Furthermore, at present it is assumed that hot layer outflow goes into the next room hot layex while the cold layer inflow goes into the fire room cold layer. When there are fires and hot layers in both rooms some inflow may go up and some outflow may go down. In fact it may eventually prove to be more accurate to split each flow between the two layers in proportion to its temperature relative to that of the two layers. If this is required, it may be important also to split plume flows between the two layers. At present there is neither theory nor experiment available as a guide on what to do.

Although holes in a floor or ceiling are not very common, they present a special problem when they do occur. So long as there are multiple holes so that the flow through the horizontal opening is one way only (in or out), simple orifice formulas and correlated flow coefficients apply. This is the assumption always made so far, but it is not always correct. Suppose there is only one hole in a fire room and it is in the ceiling. An exact analysis will always permit an equilibrium one way flow all the way down to zero flow rate. Such solutions always exist, although it is clear that for small flows they are unstable. In particular zero flow through a horizontal vent with hot air below and cold air above is unstable and is replaced by two streams in and out. The criterion which indicates whether a one way flow or a two way in, out flow is the more stable is not known. Also incompletely known is the condition which leads to puffing-an instability in the time domain $(107,108)$. None of these problems are urgent but will all have to be clarified by proper scientific study eventualiy.

The flow through the fire room vent is at present treated in zone fire models as independent of dynamic effects inside the room. There are several cases when this is not true. As already mentioned the ceiling jet inside the fire room may arrive at the wall above a vent and dynamically turn downward. If the transome wall is short, the ceiling jet, sometimes including flames may considerably alter the vent flow. If there is a fire close to the vents its plume can-greatly alter the vent flow $(21,80)$. No study, either theory or experiment, yet includes both buoyant vent flow and plume. 


\section{EXTINGUISHMENT}

Just as ading heat to a solid fuel in air can raise the temperature to ignition, so removing heat from a burning solid or liquid fuel can extinguish the fire. All the complications of phase change and pyrolysis, vaporization and charring, are present during extinguishment. Therefore as soon as we go beyond the fire triangle, remove heat, separate fuel and air (smother) alter the chemistry. (fire retardant extinguishing agent), no general theory of extinction exists; there are many extinguishment theories for the many different cases. Almost none of these potential scientific studies have ever been classified.

There are many qualitative, semi-quantitative studies of the extinguishment of crib fires, pool fires, and building fires performed by pouring on water or other agents from a sprinkler, or hose (109-111). This is essential engineering but is short on science.

A pool fire of liquid fuel (say acetone) in a channel can be extinguished by cooling the channel. It is certainly possible to develop a criterion of how much cooling is necessary by combining present knowledge of diffusion flames and heat transfer. It is equally easy to run the experiment but neither has been done.

By adding a very fine spray to a stagnation point flow onto burning charcoal (112) it was found that . $2 \%$ by mass of water can increase the burning rate by up to $30 \%$. The cause appeared to be removal of a minute ash layer. This permits the speculation that a small hose stream on a large fire may be worse than useless. Where the hose stream hits an object directly the cooling and steam vitiation puts the adjacent fire out to be sure. However, the fine spray splash moving with the residual hose and fire pumped aix into the next room may make that room burn faster. Furthermore the excess water in the first room may fall to a pile of burning charcoal on the floor and there--by the water gas reaction-produce a $\mathrm{CO}-\mathrm{H}_{2}$ mixture which will burn in the next room and enhance the fire. These notions have not yet been proven nor denied.

Only a few measurements of air pumping by hose streams have been reported (113) and nothing has been done on a theoretical prediction.

What happens as a drop of water approaches the surface of a burning object? It may evaporate before it gets there, it may splash, it may soak in and slowly evaporate as the burning is reestablished. This is an obvious study not done.

By putting water from a faucet into a frying pan containing very hot, smoking butter, the water flashes to steam, the butter is ejected as a fine spreay into the air and ignites as an explosive cloud. This actually happened and shows that some would be "extinguishment" can actually cause an ignition or increase an already bad fire.

A greatly enlarged science of extinguishment is sorely needed,

The scientific study of the performance of sprinkler systems has just begun (114-116). A sprinkler usually does not put out the fire directly because a strong buoyancy plume blows the drops away. The fire is controlled by wetting down all nearby fuels thus preventing fire spread. At the same time clouds of hot fire gases plus steam may open sprinklers at a considerable distance from the fire thus causing water damage and straining the sprinkler water supply system. clearly a real understanding of these processes by the application of scientific methods is needed. 
A11 three modes, conduction, convection, and radiation are important in fire. Conduction of heat into the interior of a fuel controls the heating rate of its surface. Thus it controls ignition and extinguishment. Such conduction is at present computed by l-dimensional linear heat diffusion. only rarely is sufficient known of the temperature dependence of the thermal properties to take this nonlinearity into account. The more complete analysis including the evaporation of moisture and pyrolysis of the virgin fuel has only been attempted a few times $(53-56,117)$. No set of equations have yet been accepted as general. The widely varying analytical descriptions of diffusive (heat and mass) heating is probably partly responsible for the wide divergence of the reported heat of pyrolysis for wood $-80<\Delta \mathrm{H}<444$ (118).

Conduction of heat is also the major effect in the weakening and collapse of steel structures in fires.

Convective heat transfer occurs wherever hot gases move over cold surfaces. The most important such heat transfer occurs where a plume hits a ceiling and produces a ceiling jet (119-121). Considerable progress has been made with this heat transfer problem.

A quite different situation applies at the base of a flame where the pyrolysis products diffuse out of the fuel surface into the gases lair, fuel, products of combustion) moving above it. The gases immediately above the surface because of its complex composition absorbs some of the feedback radiation on its way to the fuel. Thus the incident radiation at the fuel surface is reduced but because of the increased temperature of the gases there is an increase of convective heat transfer, thus partial compensation. This phenomena has not been studied in detail and the results are needed for more accurate pyrolysis rate predictions.

The floor of a fire room is heated by radiation from above. Near a vent the vent flow across the floor convectively cools it, However, away from the vent flow or other forced velocity a hot unstable layer of gas is formed which gives rise to vertical convection columns. There is no data on the distribution of the heat transfer coefficient over the floor and no adequate theory by which to calculate the cooling of the floox and heating of the cold layer.

Radiation heat transfer is by all odds the dominant mode of energy transfer in a fire. Because of this, there is intensive research on all aspects of radiation heat transfer. The physics of radiative emission and absorption by molecular and atomic bands and by soot particles (2) is well understood. Thus if an assigned volume of space is filled with a known temperature and composition distribution, the radiation from that volume to an external surface can be calculated with good precision, The theoretical formulas are well known but involve extensive calculations, too extensive for most practical purposes. The urgent need in this area of radiation from a known volume is a classification of the available approximate methods by time of calculation, precision of approximation, and spectral and other limitations. Pexhaps still better methods may yet be found.

A far more serious problem, however, is to find out how to define the appropriate radiating volume and the temperature and composition within it.

Flame height correlation formulas exist $(81,122)$ and the base of the flame is set by the burning surface of a solid or liquid fuel. But here our knowledge of flame geometry stops. How good is the commonly used cone approximation (15)? 
Is the cone hollow? or should a cylinder approximation or some fancier approximation (123) be used? Since flames of importance in fires are very unstable and nonsteady, is there not some statistical analysis which could correlate the changes of flame shape with fuel, size, rate of energy feedback, vitiation and perhaps other variables?

A knowledge of internal flame temperature and composition distribution is slowly accumulating (2). We are nowhere near a predictive capability for these quantities in a form adequate for accurate radiative transfer prediction. It is for this reason that many studies are directed toward the measurement of overall flame radiation (123) with the ultimate hope that some correlating principle will be found which will skip all the internal physical and chemical complications.

And while moving in the direction of more gross overall approximations, perhaps we can go a step further to also skip all the complex view factor calculations by some such scheme as a radiation rate pool.

The question of how much spectral knowledge is required for fire purposes has never been settled. Yet much needed facts are yet to be learned. Figures 1 and 2 show the need for careful consideration of the radiation in fire testing. For both figures, opposite sides of the same block of maple were in succession covered with the same thin $(2 \mathrm{~mm}$ ) aluminum plate containing a 2 inch hole. In Fig. I the assembly was radiatively heated by a glowbar source at about $1000 \mathrm{~K}$. In Fig. 2 a bank of tungsten wires in quartz tubes at about $2400 \mathrm{~K}$ were used. The differences in spectral response of aluminum and wood to the spectrally different heat sources is startling. We need to know more. But what and how much? Certainly some careful spectral measurements in real fires is a necessary start.

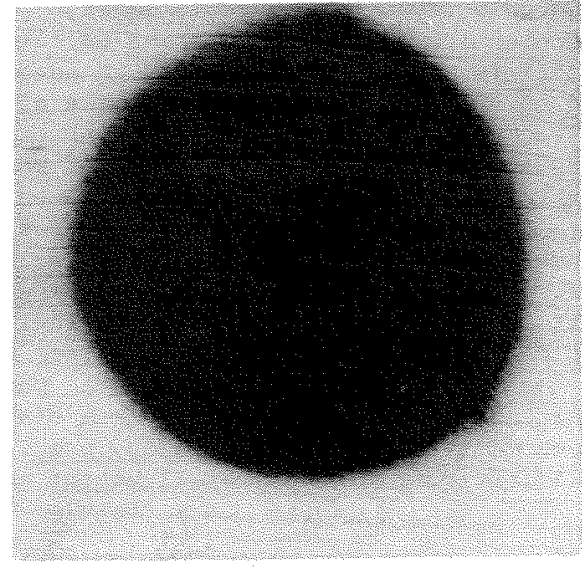

FIGURE 1. Maple block protected by an aluminum plate radiated by a glowbar unit. 


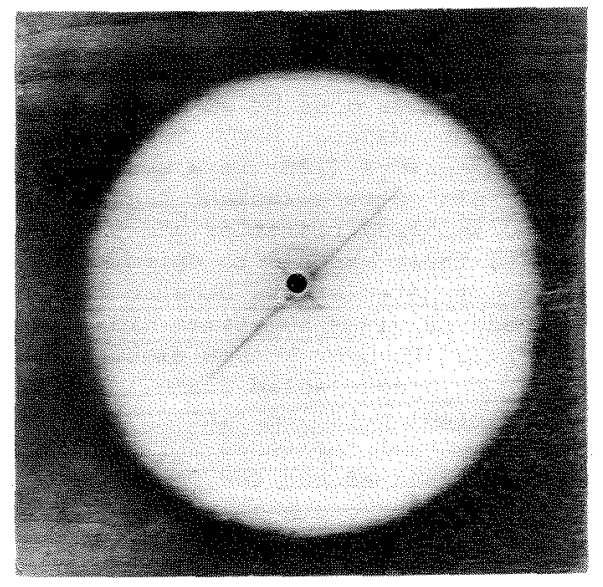

FIGURE 2. Maple block protected by an aluminum plate radiated by tungsten filaments in quartz tubes.

\section{STRUCTURAL PROBLEMS}

The heating and burning of a building structure can lead to its collapse eithex by decreased ultimate strength or increased plastic deformation (of steel structural elements) (beams, columns, reinforcing bar) or decrease of non-char cross section (wood or plastic). The science and engineering of structures has already reached an advanced stage of development. The new feature added by fire is the heating and burning of the structural elements. As soon as the fire itself can be predicted, the knowledge of heat transfer as discussed above can supply the extexnal energy distribution to a steel member while the well developed theory of heat conduction can predict its internal temperature (124). Finally the internal temperature permits prediction of the member strength and yield (125-127). Steel failure and large deflection yield are active research areas in solid mechanics and progress in this field should be followed by fire scientists.

The failure of wooden structural members is closely tied in with the pyrolysis process. It is well known that a laxge wooden beam structure can withstand more hours of a fire than an inadequately insulated steel member structure. The reason is clear. Steel is very homogeneous so that steel structures are designed with a small safety factor while wood with its knots and other internal irregularities must have a much larger safety factor. Furthermore wood has a low thermal conductivity and is thermally protected by the adhering char formed by pyrolysis. Thus building collapse prediction is not far away for steel and reinforced concrete structures but for wood much adaitional fire science is required before fire engineering can be done properly.

Collapse is of little practical importance for fire development since a builaing is usually without value before collapse occurs (in fact it may have a negative value since the burned out remains have to be torn down and carried away). However, good fire collapse predictions are important for the safety of the fixeman engaged in extinguishment. 
There is one structural problem of importance to fire growth and this is the breaking of window glass. A fire in an enclosure should never be opened to a new supply of air until a fireman with a hose stream is ready to apply water through the new vent. However, glass does break as the window is heated with or without the application of cold water. Why? The only study of this problem was carried out by two Harvard seniors (128) in a small senior proejct. They subjected $6^{\prime \prime} \times 7^{\prime \prime}$ window glass plates to a radiant heat source. As is well known, glass is relatively opaque to infrared radiation and thus becomes hot when radiated. Such a glass plate, fully exposed to uniform radiation (no shadow on the plate) gets hot all over but nevex breaks because the thermal expansion is uniform. (Actually the unshadowed glass sometimes did break because our radiation was not perfectly uniform). However window glass is as installed always held at its edges by putty or an opaque solid frame. A glass plate merely shadowed around the edge (no actual material contact to the glass) always breaks. Figure 3. It is easy to see why qualitatively. Glass is a very poor conductor and therefore if the edge is not heated but the center is, the edge is put into tension by thermal expansion. Thus a crack starts at some edge irregularity or small precrack and grows through the material in tension. It is interesting that the crack when it reaches the edge of the shaded area always bifurcates and travels through the glass along two internal stress paths. This glass breaking problem is one that has had no scientific study beyond that reported here.

\section{TOXICITY}

This is a practical problem of majox concern to fire protection engineers. However, it is often assumed to be a problem for the fire chemist and physiologist and of no concern to the fire dynamicist. This is way off the mark. It is true that the production of toxic specie is a chemist's problem and the effect on people of the toxic gases and their synergistic effects is a physiologist's problem. However, if fire engineering is ever to reach accurate design for fire safety, fire science must develop the knowledge required to predict the toxic properties in building escape routes, The present toxicity tests of materials in which a rat's (or other) nose is put into the rising plume of pyrolysis products from a heated sample of some solid gives important data.

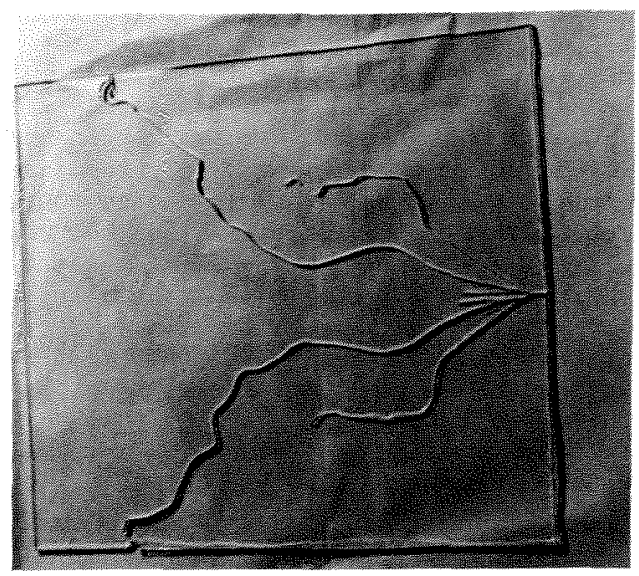

FIGURE 3. 4" square glass plate radiated by a Globar Unit with 1/4" of edge protected by a shadow. 
However, the dynamicist, together with the chemist and physiologist must somehow follow the toxic property of the gases as they move about through the building. How much of the $\mathrm{CO}, \mathrm{CH}_{3}=\mathrm{CH}_{2}-\mathrm{CHO}$, and other toxic materials initially produced are burned in subsequent flames or are lost by absorption? How much of the HCl (if any) reacts with walls or dissolves in condensed moisture? How much of the HCN is absorbed on surfaces or on soot particles? How much of the soot originally formed is bumed in subsequent. flames or agglomerates into large particles and settles out on furnishings to decrease their value but are thereby removed from their otherwise toxic mission? very few of the above questions have had any scientific study at all to date. Some fire studies have shown that $\mathrm{HCl}$ even when produced in abundance is rapidly removed to low levels (129). The mechanism of removal has not been identified. The agglomeration of soot particles has been studied in a static situation (130). However, nothing has been done with its transport throughout a building nor with its settling rate which has such a great effect on building furnishings.

Large numbers of studies of special cases have been carried out (129-138) but we do not yet have the capability of predicting the toxic hazard in an escape route during a fire.

\section{FIRE BRANDS}

The spread of a fire by the movement of burning brands is usually thought of as a forest fire problem $(139-141)$; which it is. However, it is not a problem without significance in structure fires. As a fire grows in a room, it moves quickly to the ceiling. It also heats ether flammable material throughout the room to their pilot ignition temperature. But where is the pilot? The original fire can so serve if it is close by. However, a more distant object may be pilot ignited by a burning brand from the original fire or from the ceiling area if there are flammable materials there. No studies of this problem currently exist. In fact there are no studies to answer the question of the available brands in a real fire. Since the formation of brands is an almost impossible problem deterministically, we need a suitable statistical study. Do new fuels generally ignite at their pilot ignition temperature or is it necessary for them to be heated to the higher spontaneous ignition temperature, or somewhere in between?

\section{REFERENCES}

1. Levine, R.S; Workshop on Flame Radiation and Soot, Fire Technology, 21, $14-58,1985$.

2. DeRis, J.: "Fire Radiation-A Review," 17th Symposium (Int.) on Combustion, $1003-1016,1978$.

3. Williams, F.A.: "A Review of Elame Extinction," Fire Safety JoumaZ, 3,3 , $163-176,1981$.

4. Emmons, H.W.: "Scientific Progress on Fire," Ann. Rev. Fluid Mechanics, $12,223-236,1980$.

5. Westbrook, C.K., and Dryer, F.I.: "Chemical Kinetics and Modeling of Combustion Processes," 18th Symp. (Int.) on Combustion, 749-767, 1981.

6. Quintiere, J.: "The Spread of Fire from a Compartment--A Review," ASTM Tech. Pub. , 685, 139-168, 1980. 
7. Jones, W.W.: "A Review of Compartment Fire Mode1s," NBSIR 83-2684, 1-40, 1983.

8. Hall, A. R.: "Pool Burning--A Review," Rocket Propulsion Establishment TR\#72/11, 0-82, 1972 .

9. Birky, M.M.: "Hazard Characteristics of Combustion Products in Fires: The state of the Art Review," NBSIR 77-1234, p. 1-46, 1977.

10. Flame Spread Volume--Comb. and Flame, 32, 1-4, 1983.

11. Cox, G., and Kumar, S.: "Computer Modeling of Fire," BRI (England) IP2/83, $1-5,1983$.

12. Tanaka, T.: "A Model of Multiroom Fire Spread," Fire Sci, and Tech., 3 , 2, 105-122, 1983 .

13. Visich, M.: "Consideration of Fire Development in an Enclosed Space," J. Environ. Sys. 3, 3, 215-231, 1973.

14. Sekine, T.: "Room Temperature in Fire in a Fire-Resistive Room," BRI \#29, $13-24,1959$.

15. Mitler, H.E., and Emmons, H.W.: "Documentation for Computer Fire code V," The 5th Harvard Computer Fire Code, NBS-GCR-81-344, 1-183, 1981.

16. Gahm, J.: "Computer Fire Code VI," Home Fire Project TR\#58, 1-110, 1983.

17. Chaix, J.M., and Galant, S.: "Modêle Numéxique Instantaire de la Propagation d'un Fế en Compartment Ventile," Sociétế Bertin et Cie, 1-87, 1979.

18. Reeves, J.B., and MacArthur, C.D.: "Dayton Aircraft Cabin Fire Model," vol. 1. Basic Mathematical Model, Report \#FAA-RD-76-120, 1, 1-145, 1976.

19. Smith, E.E., and Clark, M.J.: "Model of the Developing Fire in a Compartment," ASHRAE Trans., 81, Part 1, 568-58, Part 2, Development of model, $11-48,1975$.

20. Pape, R., Waterman, T.E., and Eichler, T.V.: "Development of a Fire in a Room from Ignition to Full Room Involvement," RFIRES, IITRI Proj. J6485, $1-181,1980$.

2I. Liu, V.K., and Yang, K.T.: "Undsafe II--A Computer Code for Buoyant Turbulent Flow in an Enclosure with Thermal Radiation," NBS-Grant G-7-9002 Report TR-7900, 2-78-3, 1-168, 1978 .

22. Burgan, R.E.: "Fire Danger--Fire Behavior Computations with the Texas Inst. TI59 Calculator: Users Manual," USDA Forest Service, General Tech. Rep. INT-61, 0-25, 1979.

23. Kline, S.J., Cantwel1, B.J., and Iilley, G.M.: "Complex Turbulent Flows," Vol. I, II, III, AFOSR-HTTM-Stanford Conference, 0-1550, 1980-81.

24. Patenkar, S.V., and Spalding, D.B.: "A Calculation Procedure for Heat, Mass, and Momentum Transfer in 3D Parabolic Flows," Int. J. Heat and Mass Transfer, 15, 1787-1802, 1972.

25. Launder, B.E., and Spalding, D.B.: "The Numerical Computation of Turbulent Flows, Computer Methods," in Applied Mechanics, 3, 269-289, 1974. 
26. Rehm, R.G., and Baum, H.R.: "The Equations of Motion for Thermally Driven Buoyant Flows," J. of Research NBS, 38, 3, 297-307, 1978.

27. Banksten, C.P., Casanova, R.A., Powell, E.A., and Zinn, B.T.: "The Initial Data on the Physical Properties of Smoke Produced by Burning Materials with Different Conditions," J. Fire and Flamability, 2, 165-181, 1976.

28. Lipska, A. E., and Wodley, F.A.: "Isothermal Pyrolysis of cellulose Kinetics and Gas Chromatographic/Mass Spectrometric Analysis of the Degradation Products," OCD Work Unit \#253IC, NRDL-TR-68-89, 1-37, 1968.

29. Gross, D., and Robertson, A.F.: "Self-Ignition Temperatures of Materials from Kinetic Reaction Data," J. Res. NBS, 61, 5, 413-417, 1958.

30. Beyler, C.L.: "Ignition and Burning of a Layer of Incomplete Combustion Products," Comb. Sci. and Tech., 39, 287-303, 1984.

31. Dubataki, P., Tingle, W.J., Ryszytiwskyj, w.P., and Tineliex, W.C.: "Self Ignition of Pyrolyzate-Air Mixtures," Fire Research, 1, 243-254, 1977.

32. Ohlemiller, T.J.: "Cellulosic Insulation Material, III. Effects of Heat Flow Geometry on Smoulder Initiation," Comb. Sci, and Tech, 26, 3-4, $89-105,1981$.

33. Kashiwagi, T.: "Radiative Ignition Mechanisms of solid Fuelds," Fire Safety Joumaz, 3, 3, 185-200, 1981.

34. Kashiwagi, To., and Kashiwagi, Ti.: "A Study of the Radiative Ignition Mechanism of a Liquid Fuel Using High Speed Holographic Interferometer," 19th Symp. (Int.) on Combustion, 1511-1521, 1982.

35. Kinbara, T., and Akita, K.: "On the Self-Ignition of Wood Materials," NASNRC Pub. \#786, 256-270, 1961.

36. Thomas, P.H.: "On the Surface Ignition of Self-Heating Materials," Comb. Sci. and Tech., 36, 5-6, 263-284, 1984.

37. Vega, J.M., and Liñan, A.: "Large Activation Energy Analysis of the Ignition of Self-Heating Porous Bodies," Comb. and Flame, 57, 3, 247-254, 1984.

38. Kashiwagi, T.: "Effects of Sample Orientation on Radiative Ignition," Comb. and Ftame, 44, 1-3, 223-245, 1982.

39. Alvares, N., Blackshear, P., and Kanury, M.: "The Influence of Free Convection on the Ignition of Vertical Cellulosic panels by Thermal Radiation," Comb. Sci. and Tech., 1, 407-413, 1970.

40. Quintiere, J.: "A Simplified Theory for Generalizing Results from a Radiant Pane1 Rate of Flame Spread Apparatus, "Fire and Matemials, 5, 2, $52-60,1981$.

41. Frey, A.E., and Tien, J.S.: "A Theory of Flame spread over a solid Fuel Including Finite Rate Chemical Kinetics," Comb. and Elame, 36, 263-289. 1979.

42. Borgeson, R.A.: "Flame Spread and Spread Limits," NBS-GCR-82-396, 1-52, 1.982 . 
43. Kashwagi, T., and Newman, D.L.: "Flame Spread ovex an Inclined Thin Fuel Surface," Comb. and Flame, 26, 163-177, 1976.

44. Schraufnagle, R.A, and Barlow, J.W.: "Flame Spread Rate over Polyurethane Foams," Dept. Chem. Eng., U. Texas at Austin, 1977.

45. Sibulkin, M., Kulkarni, A.K., and Annamalai, K.: Burning on a Vertical Surface with Finite Chemical Reaction Rate," Comb. and Flame, 44, I-3, 187-199, 1982 .

46. Fernandez-Pellow, A.C., Ray, R.S., and Glassman, I.: "Flame Spread in an Opposed Flow: The Effect of Ambient Oxygen Concentration," 18th Symp. (int.) on comb., 579-589, 1981 .

47. Kulkarni, A.K., and Sibulkin, M.: "Burning Rate Measurements on Vertical Fuel Surfaces," Comb. and Flame, 44, 1-3, 185-186, 1982.

48. Fernandez-Pello, A. C.: "Flame Spread Modeling," Comb. Sci. and Tech., $39,1-6,119-134,1984$.

49. Fernandez-Pello, A. C., and Hirano, T.: "Controlling Mechanisms of Flame Spread," Fire Sei. and Tech., 2, 1, 17-54, 1982.

50. Carrier, A.F., Fendell, F.E., and Feldman, P.S.: "Wind Aided Flame Spread Along a Horizontal Fuel Slab," Comb. Soi. and Tech, 23, 41-78, 1980.

51. Atreya, A.: "Fire Growth on Horizontal Surfaces of Wood," Comb. Sci. and Tech. , 39, 1-6, 40; I-4, 163-194, 1984.

52. Carrier, A.F., FendeII, F.E., and Fink, S.: "Towards Wind Aided Flame Spread Along a Horizontal Charring Slab-mhe steady Flow Problem," Comb. Sci. and Tech., 99, 999, 1983.

53. Atreya, A.: "Pyrolysis, Ignition, and Fire Spread on Horizontal Surfaces of Wood," NBS-GCR-83-449, 1-433, 1984 .

54. Kung, H.C.: "A Mathematical Model of wood Pyrolysis," Comb. and FZcme, 18, 185-195, 1972 .

55. Lee, C.K., Chaiken, R.F., and Singex, J.M.: "Charring Pyrolysis of wood in Fires by Laser Simulation," 16th Symp. (Int.) on Combustion, 1459-1470, 1976.

56. Delichatsios, M.A., and deRis, J.: "An Analytical Model for the Pyrolysis of Charring Materials," FMRC Report J.IOKOJ1.Bu, 1-20, 1983.

57. Tan, S.C.: "A Study of Transient forizontal Fire Spread over Cellular Plastics," Ph.D. Thesis, Harvard Univ. , 1-209, 1983.

58. Markstein, G.H.: "Scanning-Radiometer Measurement of the Radiance Distribution in PMMA Pool Fires," 18th Symp. (Int.) on Comb., 537-547, 1981.

59. Souil, J.M., Joulain, P, and Gengambie, E.: "Experimental and Theoretical Study of Thermal Radiation from Turbulent Diffusion Flames to Vertical Target Surfaces," Comb. Sci. and Tech., 41, 1-2, 69-81.

60. Emmons, H.W.: "The Film Combustion of Liquid Fuel," Z. Math. und Mech., $36,1 / 2,60-71,1956$. 
61. Pagni, P.J., and Shih, T.M.: "Excess Pyrolyzate," 16th Symp. (Int.) on Comb. , 1329-1343, 1976.

62. Kim, J.S., deRis, J., and Kroesser, F.W.: "Laminar Free Convective Burning of Fuel surfaces," 13th Symp. (Int.) on Comb., 949-961, 1971.

63. Adomeit, G., Hoeks, W., and Henriksen, K., "Combustion of a Carbon surface in a stagnation Point Flow Field," Comb. and Flame, 59, 3, 273-288, 1985.

64. Backovsky, J.: "The Theory of Boundary Layer Burning with Radiation," Ph. D. Thesis, Harvard Univ., 1-216, 1979.

65. Smith, E.E.: "Predicting Fire Performance Using Release Rate Information," Proc. Int. Conf, on Fire Safety, 229, 1979.

66. Bluhme, D., and Getka, R.: "Rate of Heat Release Test Calibration, Sensitivity and Time Constants of 1SO RHR Apparatus," Nordtest-Proj. 1.15-77, 1982.

67. Thomas, P.H.: "On the Rate of Burning of Cribs," BRI (England), Fire Res. Note $965,1-17,1973$.

68. Orloff, L., and deRis, J.: "Modeling of Ceiling Fires," 13th Symp. (Int.) on Comb., 979-992, 1971.

69. Modak, A.T., "The Burning of Large Pool Fires," Fire Safety J., 3, 3, $177-184,1981$.

70. Sibulkin, M., and Tewari, S.S., "Measurement of Flaming Combustion of Pine and Fire Retarded Cellulose," Comb. and Flane, 59, 1, 31-42, 1985.

71. Kimbara, T., Endo, H., and Sega, S.: "Combustion Propagation Through Solid Materials, I, Downward Propagation of Smouldering along a thin sheet of Paper, 11th Symp. (Int.) on Comb., 525-531, 1.966.

72. Moussa, N.A., Toong, T.Y., and Garris, C.A.: "Mechanism of Smouldering of Cellulosic Materials," 16th Symp. (Int.) on Comb., 1976.

73. Bilger, R.W.: "Turbulent Jet Diffusion Flames," Prog. in Energy and Comb. Sci., 1, 87-109, 1976.

74. Jeng, S.M., Chen, L.D., and Faeth, G.M.: "An Investigation of Axisymmetric Buoyant Turbulent Diffusion Flames," NBS-GCR-82-367, 1-83, 1982.

75. Morton, B.R., Taylor, G.I., and Turner, J.S.: "Turbulent Gravitational Convection from Maintained and Instantaneous Sources," Proc. Roy. Soc. Ser. A234, 1196, 1956.

76. Lee, S.I., and Emmons, H.W.: "A Study of Natural Convection above a line Fire," J. Fluid Mech., 11, 353-368, 1961.

77. Cetegen, B.M., Zukoski, E.E., and Kubota, T.: "Entrainment in the Near and Far Field of Fire plumes," Comb. and Flame, 39, 1-6, 40; 1-4, 305-332, 1984.

78. Beyler, C.L.: "Development and Burning of a Layer of Products of Incomplete Combustion Generated by a Buoyant Diffusion Flame," Ph. D. Thesis, Harvard univ., 1-169, 1983 (see p. 57). 
79. Liburdy, J.A., Ahmad, T., and Faeth, G.M.: "An Investigation of the overfire Region of Wall Fires," Eastern Section Conf., 1-15, 1976.

80. Emmons, H.W.: "The Ingestion of Flames and Fire Gases into a Hole in an Aircraft Cabin for Arbitrary Tilt Angles and wind Speeds," Home Fire Froject Report 52, 1-33, 1982 .

81. Stewart, F.R.; "Prediction of the Height of Turbulent Diffusion Buoyant Flames," Comb. Sci. and Tech., 2, 203-212, 1970.

82. Tamanini, F.: "An Integral Model of Turbulent Flame Plumes," 18th Symp. (Int.) on Combustion, 1081-1090, 1981.

83. Evans, D.D.: "Calculating Fire Plume Characteristics in a Two Layer Environment," Eire Technology, 20, 3, 39-63, 1984.

84. Heskestadt, G.: "Virtual Origins of Fire Plumes," Fire Safety J., $\underline{5}, 2$, $109-114,1983$.

85. Quinture, J.R., Rinkinen, W.J., and Jones, W.W.: "The Effect of Room Openings on Fire Plume Entrainment," Comb. Sei, and Tech., 26, 3-4, $193-201,1981$.

86. Zukoski, E.E., Kubota, T., and Cetegen, B.: "Entrainment in Fire plumes," Fire Safety J., 3, 107-121, 1980.

87. Rao, V.K.: "The Buoyant Plume above a Heat Source," Atmo. Environ., 4, $557-575,1970$.

88. Varma, R.K., Murgai, M.P., and Ghildyal, C.D.: "Radiative Transfer Effects in Natural Convection above Fires--General Case," Proc. Roy. Soc. London Ser. A314, 195-215, 1970.

89. Tsang, G., and Wood, I.R.: "Motion of Two-Dimensional starting Plume," $J$. Eng. Mech. Div. Proc. ASCE, 1547-1561, 1968.

90. Baum, H.R., Rehm, R.G., Barnett, P.D., and Carley, D.M.: "Finite Difference Calculations of Buoyant Convection in an Enclosure. I. The Basic Equations," SIAM J. Sei. Stat. Comput., 4, 1, 117-135, 1983.

91. Rehm, R.G., Baum, H.R., and Barnett, P.D.: "Buoyant Convection Computed in a Vorticity, stream Function Formulation," J. of Research NBS 87, 2, $165-185,1982$,

92. Torrance, K.E.: "Natural Convection in Thermally Stratified Enclosures with Localized Heating from Below," J. Fluid Mech., 95, 3, 477-495, 1979.

93. Jaluria, Y.: "Buoyancy Induced Wall Flow Due to Fire in a Room," NBSIR $84-2841,1-93,1984$.

94. Cooper, L.: "On the Significance of a Wall Effect in Enclosures with Growing Fires," Comb. Sci. and Tech., 40, 19-36, 1984.

95. Coward, H.F., Carpenter, C.W., and Payman, W.: "The Dilution Limits of Inflammation of Gaseous Mixtures," J. Chem. Soc., 115, 27, 1919.

96. Alpert, R.: "Turbulent Ceiling Jet Induced by Large Scale Fires," Comb. Sei. and Tech., 11, 197-213, 1975. 
97. Ellison, T.J., and Turner, J.S.: "Turbulent Entrainment in stratified Flows," J. Fluid Mech. , 6, 423-448, 1959.

98. Atallah, s.: "Fire in a Model Corridor with a simulated Combustible Ceiling, Parts 1, 2," BRI Note 620,621, 1-31, 1-21, 1966.

99. Hwang, C.C., Chaiken, R.F., Singer J.K., and Chi, D.N.H.: "Reverse stratified Flow in Duct Fires--A Two Dimensional Approach," 16th Symp. (Int.) on Combustion, 1385-1395, 1976.

100. Baum, H.R., Rehm, R.G., and Malholland, G.w.: "Prediction of Heat and Smoke Movement in Enclosure Fires," Fire Safety J., 6, 3, 193-201, 1983.

101. Jones, W.W., and Quinture, J.: "Prediction of Corridor Smoke Filling by zone Models," Comb. Sci. and Tech. , 35, 5-6, 239-253, 1984.

102. Emmons, H.W.: "A Perfect Fluid Non-Steady Ceiling Jet," to be published.

103. Prahl, J., and Emmons, H.W.: "Fire Induced Flows Thru an Opening," Comb. and Elame, 25, 3, 369, 1975.

104. Steckler, K.D., Baum, H.R., and Quintiere, J.: "Fire Induced Flows Thru Room Openings--Flow Coefficients," 20th Symp. (Int.) on Comb., 1984, to be published.

105. Quintiere, J., Den Braven, K.: "Some Theoretical Aspects of Fire Induced Flows through Doorways in a Room-Corridor Scale Model, "NBSIR78-1512, $1-33,1978$.

106. Nakaya, I., Tanaka, T., and Yashida, M.: "A Measurement of Doorway Flow Induced by Propane Fire," 7th Meeting UJNR, Washington, 1983.

107. Satoh,...: "Experiment and Finite Difference study of Dynamic Fire Behavior in a Cubic Enclosure with a Doorway," BRI 55, 17-28, 1983.

108. Hasemi, Y.: "Thermal Instability in Transient Compartment Fire," Fire Sei. and Tech., 2, 1, 1-16, 1982.

109. Rasbash, D.J.: "The Extinction of Fires by Water Sorays," Fire Res, Abs. \& Res. , $4,28,1982$.

110. Kung, H.C.: "Cooling of Room Fixes by Sprinklex Spray," J. Heat Transfer, $99,3,355-359,1977$.

111. Takahashi, s.: "Extinction Mechanism and Efficiency by Sprays of water and Chemically Improved Water," Fire Res. Inst. (Japan) Ser. 56, 7-11, 1983.

112. Bhagat, P.M.: "Wood Charcoal Combustion and the Effects of Water Application," Comb. and Flame, 37, 3, 275-291, 1980.

113. Heskestad, G., Kung, A.C., and Tottenkopf, N.F.: "Air. Entrainment into Water Sprays and Spray curtains," ASME 76-WA-FE40, 0-12, 1976.

1.14. Alpert, R. I.: "Calculated Interaction of Sprays with Large-Scale Buoyant Flows," J. Heat Trans., 106, 2, 310-317, 1984.

115. Evans, D.D.: "Thermal Actuation of Extinguishing Systems," Comb. Soi. and Tech. $40,79-92,1984$. 
116. Yuen, M.C., and Chen, L.W.: "On Drag of Evaporating Droplets," Comb. Sei. and Tech. 14, 147-154, 1976.

117. Min, K., and Emmons, H.W.: "The Drying of Porous Media," Proc. 1972 Heat and Trans. and Fluid Mech. Inst., p. 1-18, 1972

118. Shivadev, U.K., and Emmons, H.W.: "Thermal Degradation and Spntaneous Ignition of Paper Sheets in Air by Irradiation," Comb. and Flame, 22, 223-236, 1974.

119. You, H.z., and Faeth, G.M.: "Ceiling Heat Transfer during Fire Plume Impingement," Fire and Materials, 3, 3, 140-147, 1979.

120. Zukoski, E.E., and Kubata, T.: "An Experimental Investigation of the Heat Transfer from a Buoyant Plume to a Horizontal Ceiling, "NBS-GCR-77-98, $1-73,1975$.

121. Cooper, I.Y.: "Heat Transfer from a Buoyant Plume to an Unconfined Ceiling," J. Heat Trans. 104, 3, 446-451, 1982.

122. Thomas, P.H.: "The size of Flames from Natural Fires," 9th Symp. (Int.) on Comb. , 844-859, 1963 .

123. Orloff, I.: "Simplified Modeling of Pool Fires," 18th Symp. (Int.) on Comb., $549-561,1981$.

124. Lie, T.T.: "Temperature Distributions in Fire Exposed Building Columns," J. Heat Trans., 99, 1, 113-1.19, 1977.

125. Becker, J.M., and Bresler, M.: "Reinforced Concrete Frames in Fire Environments," J. Structural Div. ASCE, 211-224, 1977.

126. Kawagoe, K.: "Damage of Structures in Full Size Fires," BRI (Japan) Ser. $29,27-41,1959$.

127. Saito, H.: "Explosive Spalling of Prestressed Concrete in Fire," BRI (Japan) Ser. $22,1-18,1965$.

128. Barth, P.K., and Sung, H.T.: "Glass Fracture under Intense Heating," Senior Proj. Es96r, Harvard Univ. , 1977.

129. Staxk, G.W., and Field, P.: "Toxic Gases and smoke from Polyvinylchloride in Fixes in the FRS Full scale Test Rig," BRI (England), Fire Research Note $1030,0-48,1974$.

130. Mulholland, G.W., and Baum, H.R.: "Effect of Initial Size Distribution on Aerosol Coagulation," Phys. Rev. Letts., 45, 761, 1980.

131. Pagni, P.J., and Bard, S.: "Particulate volume Fractions in Diffusion Flames," 17th Symp. (Int.) on Comb., 1017-1028, 1979.

132. Marikawa, T.; "Toxic Hazards of Acrolein and Carbon Monoxide Evolved under Various Combustion Conditions," BRI (Japan) Ser. 57, 21-27, 1984.

133. Tsuchiya, Y., and Boulanger, J.G.: "Carbonyl sulfide in Fire Gases," Fire and Materiats, 3, 3, 154-155, 1979.

134. Tsuchiya, Y.: "Significance of Hydrogen Cyanide Generation in Fire Gas Toxicity," J. Comb. Toxicology, 4, 271-282, 1977. 
135. Marikawa, T.: "Effect of Water Vapor on Carbon Monoxide Evolution in Fire Conditions," BRI (Japan) Ser. 53, 1-8, 1983.

136. Woolley, W.D., Fardell, P.J., and Buckland, I.G.: "The Thermal Decomposition Products of Rigid Polyurethane Foams under Laboratory Conditions," BRI (England), Note 1039, 1974.

137. Shafizadeh, E.: "Thermal Behavior of Carbohydrates," J. Potymer Sci., 36, $21-51,1971$.

138. Tewarson, A., Lee, J.L., and Pion, R.F.; "The Influence of oxygen Concentration on Fuel parameters for Fire Modeling," 18 th Symp. (Int.) on Comb., 563-570, 1981 .

139. Tarifa, C.S.: "On the Flight Paths and Lifetimes of Burning Particles of Wood," 10th Symp. (Int.) on Comb., 1021-1037, 1965.

140. Tarifa, C.S.: "Transport and Combustion of Fire Brands," FinaI Report Proj. FG-SP-114, Forest Service, U.S. Dept. of Agri., 1-90, 1967.

141. Muraszew, A.: "Firebrand Phenomena," Aerospace Corp. Report \#ATR-77, $(8165-01)-1$. 
